\title{
Biological Activities of Recombinant Liver X Receptor $\beta$ - Ligand Binding Domain Protein in Tetracycline-Inducible Expression System
}

\author{
Hyun Kang \\ Department of Medical Laboratory Science, College of Health Science, Dankook University, Cheonan-si, Chungnam, 330-714, \\ Republic of Korea \\ ${ }^{*}$ For correspondence: Email: hkang@dankook.ac.kr; Tel: +82-41-550-1452; Fax: +82-41-559-7934
}

Received: 11 May 2014

Revised accepted: 9 July 2014

\begin{abstract}
Purpose: To investigate tetracycline-inducible expression system for producing clinically usable, highquality liver $X$ receptor ligand-binding domain recombinant protein

Methods: In this study, we have expressed and purified the recombinant liver $X$ receptor $\beta$-ligand binding domain proteins in E. coli using a tetracycline inducible system. To allow for biological activities, we subcloned into pPROTet.E HN vector, expressed in E. coli cells under optimized conditions, purified and characterized the recombinant liver $X$ receptor $\beta$-ligand-binding domain proteins using fluorescence polarization assay.

Results: The use of pPROTet.E HN vector simplified downstream purification processes, including cleavage and elution thereby increasing the solubility and yield of the protein of interest. There was a 2.3-fold increase in the efficiency of recombinant $L X R \quad \beta$-ligand binding domain (LBD) production by optimizing the expression temperature to $15^{\circ} \mathrm{C}$ when compared to those induced at $37^{\circ} \mathrm{C}$ during the induction procedures. A typical dose-response curve obtained using increasing concentrations of the purified recombinant LXR $\beta$-LBD (197-461) and measuring fluorescence intensity (FI) as an index of fluorescent peptide binding to $L B D$ showed $50 \%$ effective dose $\left(E D_{50}\right)$ value of $533 \mathrm{nM}$. The recombinant $L X R \quad \beta-L B D$ s were substantially soluble and should be useful for future biological, biophysical and structural analyses of nuclear receptor complexes. This may represent a new approach to high expression of other nuclear receptors and may be useful as well for other classes of heterodimeric protein partners.

Conclusion: These findings indicate that recombinant $\angle X R \beta-L B D$ protein is a promising target for the development of molecular ligands with improved therapeutic windows.
\end{abstract}

Keywords: Nuclear receptor, Recombinant $L X R \quad \beta-L B D$, Tetracycline-inducible expression system, Fluorescence polarization assay

Tropical Journal of Pharmaceutical Research is indexed by Science Citation Index (SciSearch), Scopus, International Pharmaceutical Abstract, Chemical Abstracts, Embase, Index Copernicus, EBSCO, African Index Medicus, JournalSeek, Journal Citation Reports/Science Edition, Directory of Open Access Journals (DOAJ), African Journal Online, Bioline International, Open-J-Gate and Pharmacy Abstracts

\section{INTRODUCTION}

Members of the lipophilic hormone nuclear receptor superfamily including the receptors for retinoic acid, vitamin $\mathrm{D}$, thyroid hormone, and steroid hormones are hormone-activated transcription factors that play pivotal roles in a wide variety of physiological processes, such as growth, reproduction, development, differenttiation, metabolism and homeostasis [1,2]. A subgroup of receptors within the superfamily, including the retinoic acid receptor (RAR), thyroid hormone receptor (TR), vitamin $D$ receptor (VDR), peroxisome proliferator activated receptor 
(PPAR), and many orphan receptors, bind to specific DNA sequences known as hormone response elements as heterodimers with the retinoid $X$ receptor (RXR) [1]. Along with the highly conserved DNA-binding domain (DBD) and a carboxy-terminal domain that specifies both ligand binding and receptor dimerization (LBD), these receptors also contain regions required for transcriptional activation (AF-1 and $A F-2)$. Liver $X$ receptor ( $L X R$, consisting of two members, LXR $\alpha$ and LXR $\beta$ ) is an orphan receptor that heterodimerizes with $R X R$ and binds to a specific response element called the LXRE [4]. Both LXRs are widely expressed in multiple tissues and cell types, while LXR a most highly expressed in liver and intestine [5]. The natural ligands for LXRs consisted of a select group of oxysterols derived from tissue-specific cholesterol metabolism in the liver, brain, and gonads [6]. Development of LXR ligands as therapeutic agents has been hampered because dual LXR agonists induce an increase in hepatic triglyceride production [10]. Because LXR $\alpha$ is the dominant subtype in the liver, where $L X R \beta$ is expressed at very low levels, it is thought that an LXR $\beta$-selective agonist may retain efficacy without deleteriously increasing hepatic lipogenesis [12]. Actually LXR a leads to stimulation of fatty acid synthesis pathways and increased triglyceride levels. Hence, the identification of LXR $\beta$-selective agonists may be of significant therapeutic values. Thus, we decided to express and purify the recombinant LXR $\beta$-LBD proteins in E. coli using a tetracycline (Tet)-inducible expression system. We describe here the expression, purification and its biological activity. This suggests that the Tet-inducible expression system improve their solubility and probably assists the correct folding working.

\section{EXPERIMENTAL}

\section{Preparation of expression constructs}

For the expression of (His)6-tagged LXR $\beta$-LBD, cDNA fragments encoding for human $L X R \beta-L B D$ were obtained by RT-PCR and subcloned into pPROTet.E HN vector (Clontech Laboratories,
Mountain View, CA, USA) using the BamHI/Hindlll sites. The oligonucleotide primers used for PCR-based cloning of various length of LXR $\beta$-LBD are shown in Table 1.

\section{Protein expression and purification}

Tetracycline (Tet)-inducible expression constructs for four kinds of LXR $\beta$-LBD were transformed into BL21 (DE3) Pro cells (InVitrogen, Carlsbad, CA, USA). Cultures were grown at $37{ }^{\circ} \mathrm{C}$ in $\mathrm{LB}$ medium containing chloramphenicol and spectinomycin. These cultures were induced at an optical density at $600 \mathrm{~nm}$ of $0.8-1.0$ and then cooled to the induction temperature at $15{ }^{\circ} \mathrm{C}$. The cultures were added anhydrotetracycline at a final concentration of $200 \mathrm{ng} / \mathrm{ml}$ and grown for a further 4-5 $\mathrm{h}$ before harvesting by centrifugation. The cell pellet was frozen, then resuspended in the buffer containing 20 mM HEPES, $\mathrm{pH} 8.0,100$ $\mathrm{mM} \mathrm{KCl}, 20 \mathrm{mM}$ imidazole and Protease Inhibitor CocktailTM (Roche Diagnostic, Manheim, Germany) for purifying six histidine ((His)6)tagged proteins, and lysed by sonication. The lysate was cleared by centrifugation and loaded at $4{ }^{\circ} \mathrm{C}$ onto $\mathrm{Ni}^{+2}$ nitrilotriacetate acid (NTA) agarose column (ProbondsTM Resin, Invitrogen). The $\mathrm{Ni}^{+2}$-NTA agarose column was washed the buffer containing $20 \mathrm{mM}$ HEPES, pH 8.0, 100 $\mathrm{mM} \mathrm{KCl}, 20 \mathrm{mM}$ imidazole. The proteins were eluted from the column in the same buffer containing the appropriate concentration of imidazole.

\section{Solubility analysis}

E. coli cell pellets were resuspended in the 20 mM HEPES, pH 8.0, $100 \mathrm{mM} \mathrm{KCl,} 1$ mM EDTA and Protease Inhibitor CocktailTM, ultrasonicated, and then centrifuged at 3,000 $\mathrm{xg}$ for $20 \mathrm{~min}$ to remove intact cells and cell debris. The supernatants were then further centrifuged at $10,000 \times \mathrm{g}$ for $15 \mathrm{~min}$ to precipitate the insoluble proteins. Soluble proteins were purified from the supernatant using the appropriate affinity resin.

Table 1: Primer sequences for the RT-PCR of each recombinant LXR-LBD fusion protein

\begin{tabular}{|c|c|}
\hline Primer & Sequence \\
\hline Sense & \\
\hline S-LXR $\beta-$ LBD $_{(197-461)}$ & 5'-CGCGGATCCCCTGGGGCTTCCCCTGGTGGA-3' \\
\hline S-LXR $\beta-$ LBD $_{(205-461)}$ & 5'-CGCGGATCCGAGGCAGGCAGCCAGGGCTC-3' \\
\hline S-LXR $\beta-$ LBD $_{(214-461)}$ & 5'-CGCGGATCCGGCGAGGGTGTCCAGCTAACA-3' \\
\hline$S-L X R \beta-\operatorname{LBD}_{(220-461)}$ & 5'-CGC $\frac{\overline{\text { GGATCCACAGCGGCTCAAGAACTAATGAT-3' }}}{\text { BamHI }}$ \\
\hline Common anti-Sense & 5'-CGCAAGCTTTCACTCGTGGACGTCCCAG-3 \\
\hline AS-LXR $\beta-L B D$ (common) & HindIIII \\
\hline
\end{tabular}


Ligand binding analysis using fluorescence polarization assays

Fluorescence polarization assays were performed using a Victor apparatus (PerkinElmer Life and Analysis Sciences, Boston, MA, USA) according to the method described by Dagher et al [13] and Lévy-Bimbot et al [14]. Assays were conducted in 96-well black polystyrene plates. The effects of T-0901317 on the interaction of the coactivator peptide (SRC1a, CPSSHSSLTERHKILHRLLQEGSPS, Cosmo Genetech Co., Seoul, Korea) and the acceptor APC with LXR $\beta$-LBD were determined by fluorescence polarization assays in the assay buffer. Varied concentrations of LXR $\beta$-LBD in the presence or absence of T-0901317 were incubated at room temperature with a europirimlabeled peptide. The polarization degrees (FI) were measured with an excitation wavelength set at $615 \mathrm{~nm}$ and an emission wavelength set at $665 \mathrm{~nm}$. The apparent dissociation constant values were determined by the binding curves derived from a nonlinear least-squares-fit of the data for a sample 1:1 interaction.

\section{Western blot analysis and antibodies}

Equal amounts of protein were loaded onto $12 \%$ PAGE gels and separated by standard SDSPAGE procedure. Proteins were transferred to a nitrocellulose membrane (S\&S, Dassel, Germany) and blocked with $5 \%$ non-fat dry milk in TBS. Then, the blots were probed with the specific antibodies against (His)6 tag and LXR $\square$ followed by the secondary antibodies coupled to horseradish peroxidase (Bio-Rad, Hercules, CA, USA). The immunoreactive proteins on the membrane were detected by chemiluminescence using the Western Blotting Detection Reagent Kit (AbSignalTM, AbClon Co., Seoul, Korea). The antibodies were purchased from Cell Signaling Technology (Beverly, MA, USA).

\section{Statistical analysis}

The statistical analysis was performed using the Student paired t test. $P<0.05$ were considered statistically significant. Average values were expressed as mean \pm SD.

\section{RESULTS}

\section{Comparison of nuclear hormone receptors' ligand binding domains}

The ligand binding domains (LBDs) of the various nuclear hormone receptors are depicted in Figure 1. The arrows indicate the starting amino acid residues for four kinds of recombinant
LXR $\beta$-LBD protein. The arrows indicate the starting amino acid residues for each recombinant LXR $\beta$-LBD. We generated four different constructs of 197, 205, 214 and 220 recombinant LXR $\beta$-LBD in pPROTet.E HN vector.

\section{Expression of LXR $\beta$-LBD proteins from PLtetO-1 promoter in pPROTet.E HN vector}

The LXR $\beta$-LBD with various length of amino acid residues were subcloned into a pPROTet.E $\mathrm{HN}$ tetracycline inducible expression vector to produce receptor tagged $\mathrm{N}$-terminally by six histidine residues (His)6 (Figure 2A). The correct constructs were transformed into the expression host E. coli BL21 (DE3) Pro cells, and subjected to a pilot expression test. As shown in Figure 2B, there was an obvious protein band for LXR $\beta$ $\operatorname{LBD}_{(205-461)}$ after tetracycline induction at the concentration from $100 \mathrm{ng} / \mathrm{ml}$ that could be detected by anti-(His) 6 antibody according to Western blot analysis. The apparent molecular weight of the LXR $\beta-$ LBD $_{(205-461)}$ fusion protein was about $30 \mathrm{kDa}$. The fusion protein was same efficient production induced by the concentration from $100 \mathrm{ng} / \mathrm{ml}$ at $37^{\circ} \mathrm{C}$, and it was chosen for the purification experiment soon after simple cultivation, short doubling time (rapidity) and inexpensiveness. Here, we report a method that produces the recombinant protein as the soluble fraction by using a tetracycline inducible $E$. coli expression system. Because the soluble fraction is directly applied to $\mathrm{Ni}^{+2}-\mathrm{NTA}$ column, it has an advantage. In addition, use of the pPROTet.E HN vector further simplifies downstream purification processes, including cleavage and elution. Thus this experimental approach may be helps to increase the solubility and yield of the protein of interest.

\section{Increased efficiency of recombinant LXR $\beta$ - LBD production by optimizing the expression temperature during the induction procedures}

The transformed $E$. coli cells were grown at 37 ${ }^{\circ} \mathrm{C}$ and induced with anhydrotetracycline at $37^{\circ} \mathrm{C}$ or $15^{\circ} \mathrm{C}$ until the absorbance reached 0.8 at 600 $\mathrm{nm}$. After induction the cells were harvested by centrifugation. Uninduced cells were also grown without the inducer as control. The soluble protein extracts were analyzed by standard SDSPAGE procedure and subjected the Western blot analysis with antibody against LXR. As shown in Figure 3, the expressions of four types of LXR $\beta$ $\operatorname{LBD}_{((197-461),(205-461),(214-461) \text {, and (220-461)) }}$ induced at $15^{\circ} \mathrm{C}$ was about 2.3 fold higher than those induced at $37{ }^{\circ} \mathrm{C}$ judging from the analysis by Western blot analysis with antibody against LXR. 
IXR beta IBD IXR alpha IBD RAR alpha IBD RAR gama IBD

VDR IRD

PPAR gama IBD PPAR delta IBD RXR alpha IBD AR IBD
197(P) $205(\mathrm{E}) \quad 214(\mathrm{G}) \quad 220(\mathrm{~T})$

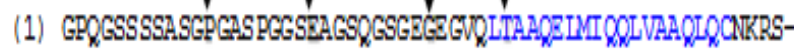

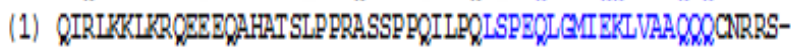

(1)

(1)

(1) -BSYILTPEVESIIEKVRRAHQZT FPALCQICKYTTN-DGYELSPDIZELITKVSKAHOETFPSLCDIGKYTTN-

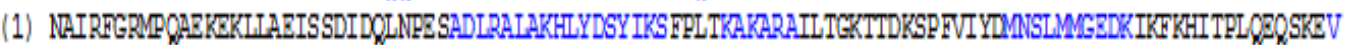

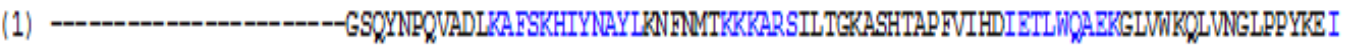

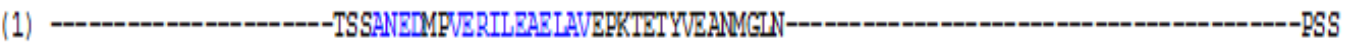

(1) SSTTSPTEETTQRLTVGHIEGYCCPITLNVIEAIEPGWCAETENIPRDS
IXR beta IBD LRR alpha IBD RAR alpha IBD RAR gamma IBD

VDR IBD PPAR gama IBD PPAR delta IBD RXR alpha IBD AR IBD

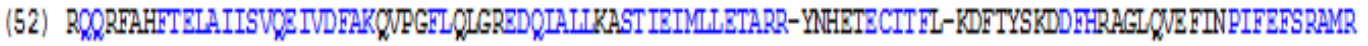

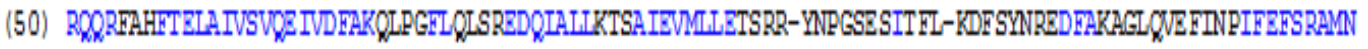

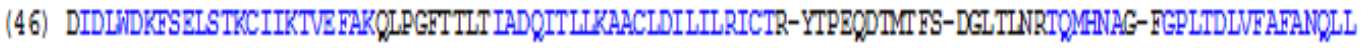

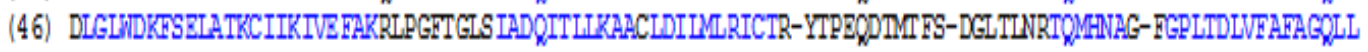

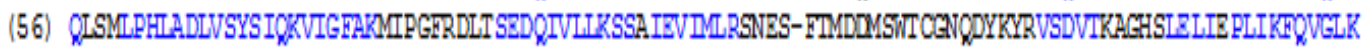

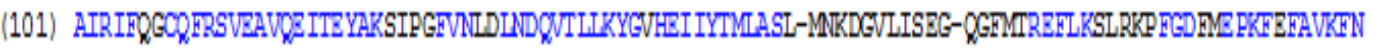

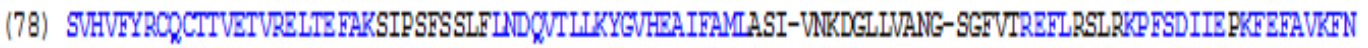

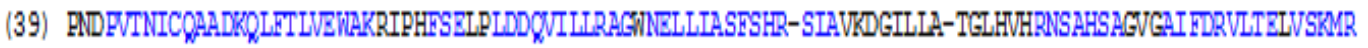

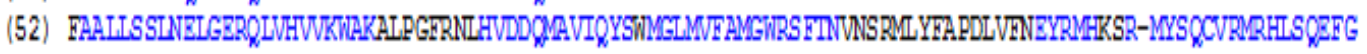

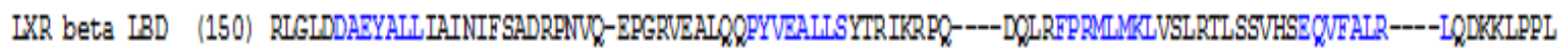

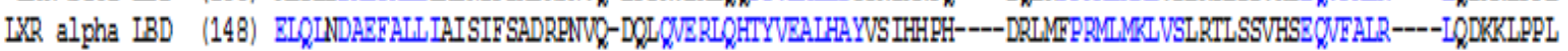

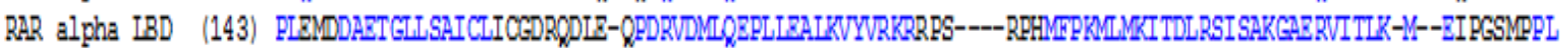

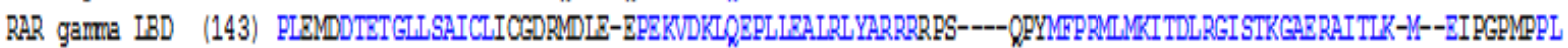

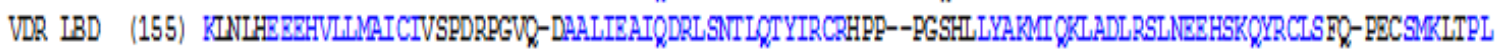

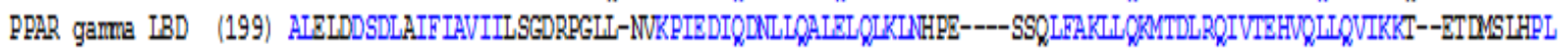

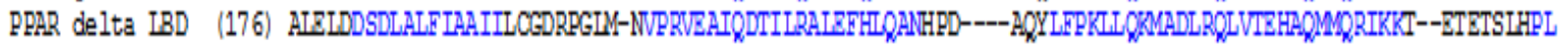

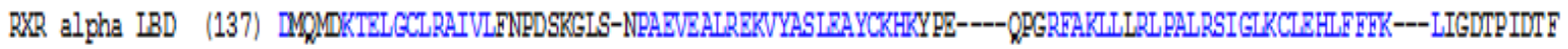

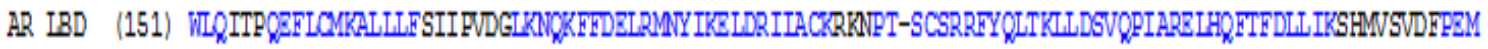

\begin{tabular}{|c|c|}
\hline LXR beta IBD & (241) LSEINDVE- \\
\hline IXR alpha IBD & 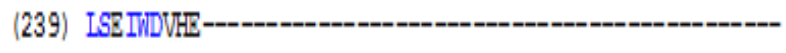 \\
\hline RAR alpha IBD & (235) IOZMIZNSEGLDTISGQPGCGGRDGGGIAPPPGSCSPSLSPSSNRSSPAIHSP- \\
\hline RAR gama IBD & 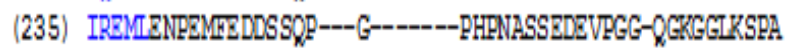 \\
\hline VDR IBD & (251) VIEVRGNEIS--- \\
\hline PAR gama IBD & (292) LQZTYKDLY--- \\
\hline DAR delta IBD & (269) IQRTYKDMY-----. \\
\hline RXR alpha IBD & (229) IVEMEAPHQMI-------------- \\
\hline AR IBD & 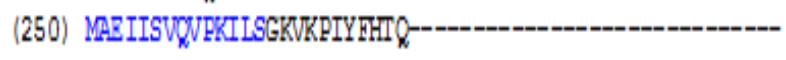 \\
\hline
\end{tabular}

Figure 1: Ligand binding domains (LBDs) of various nuclear hormone receptors. The arrows indicate the starting amino acid residues for four kinds of recombinant $L X R \beta-L B D$ protein. The arrows indicate the starting amino acid residues for each recombinant $L X R \beta-L B D$ 


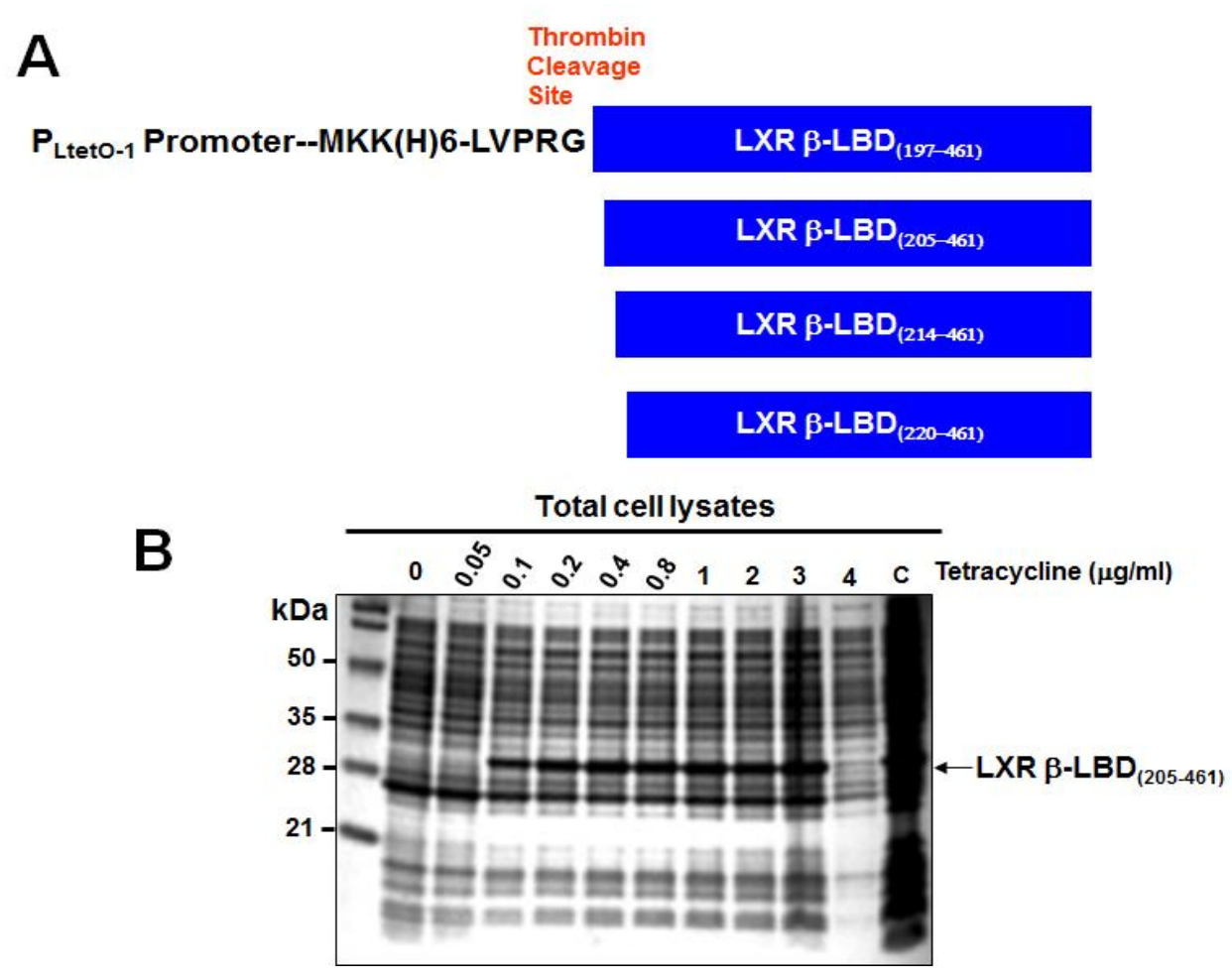

Figure 2: Schematic diagram of expression constructs (A) and analysis of expressed fusion protein by SDSPAGE (B). (A): The overall organization of the variable lengths of LXR $\beta$-LBD is shown in schematic diagram. All $\operatorname{LXR~} \beta-\operatorname{LBD}((197-461) \text {, (205-461), (214-461), and (220-461)) are tagged with (His) })_{6}$ residues at their $\mathrm{N}$-termini. (B): The total cell lysates from $E$. coli cells induced with each concentration of the anhydroteracycline, as inducer, indicated were separated onto standard SDS-PAGE gel and stained with Coomassie Brilliant Blue R-250. The arrow indicates the expressed recombinant LXR $\beta-\operatorname{LBD}_{(205-461)}$. Lane $C$ represents the total extract from the uninduced $E$. coli cells

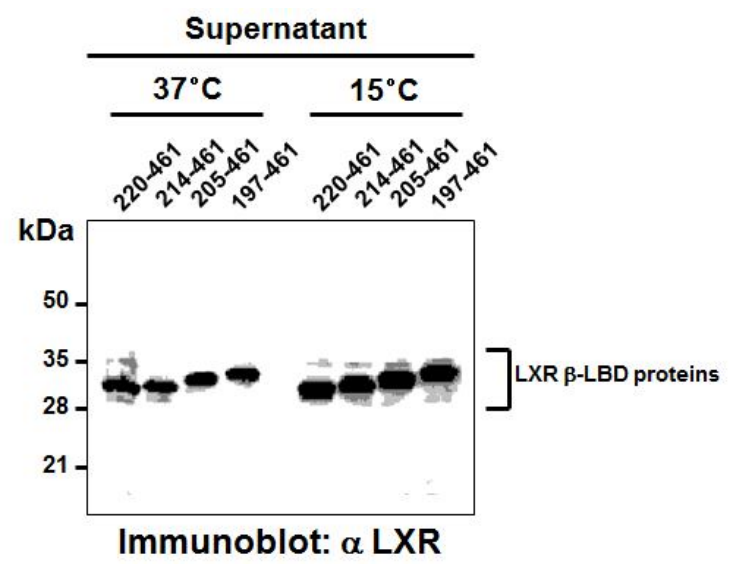

Figure 3: Lowing temperature increases the solubility of various length of recombinant LXR $\beta$-LBD protein expressed using tetracycline-inducible system. E. coli

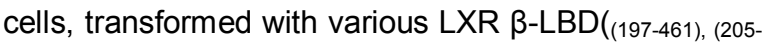
461), (214-461), and (220-461)) expression constructs, were harvested after induction at 37 or $15^{\circ} \mathrm{C}$, and lysed. The soluble fractions were separated by SDS-PAGE and subjected to immunoblot analysis with antibody against LXR

\section{Effect of the presence of agonist on expression of recombinant LXR $\beta$-LBD fusion protein and purification}

To explore the possibilities of a synthetic agonist, $\mathrm{T}-0901317$, as a stabilizing additive during the expression and induction of recombinant LXR $\beta$ LBD fusion protein, we introduced this synthetic agonist at various stages of the expression and purification procedure. Addition of a synthetic LXR agonist T-0901317 to the expression culture media and to all buffers used for lysis, and purification. The recombinant LXR $\beta-\operatorname{LBD}_{(197-461)}$ fusion protein induced or uninduced at $15^{\circ} \mathrm{C}$ in the presence or absence of a synthetic agonist T-0901317 and separated by SDS-PAGE and stained with Coomassie Brilliant Blue R-250. As shown in Figure 3, expression of the recombinant LXR $\beta-\mathrm{LBD}_{(197-461)}$ fusion protein induced in the presence of T-0901317 exhibited the efficient production in soluble fraction, whereas the recombinant LXR $\beta-\operatorname{LBD}_{(197-461)}$ is majorly insoluble when expressed in the absence of this synthetic agonist. The LXR $\beta$-LBD was found to be soluble and expressed at a relatively high level by adding its synthetic agonist, T-0901317, 
to the expression culture media and to all buffers used for lysis (Figure 4).

E. coli, transformed with various $\mathrm{LXR} \beta-\mathrm{LBD}_{(197-}$ 461), was harvested after induction at $15^{\circ} \mathrm{C}$. The bacterial lysate obtained using an ultrasonicator, after clarification by centrifugation, was loaded onto $\mathrm{Ni}^{+2}$-NTA agarose column. The column resin was then washed until no protein was found in the eluate (Figure 5, Fraction \#1-4). The (His)6-fused LXR $\beta-$ LBD $_{(197-461)}$ obtained using $\mathrm{Ni}^{+2}$-NTA-agarose column was cleaved by thrombin. LXR $\beta-\mathrm{LBD}_{(197-461)}$ was purified, separated by SDS-PAGE gels and visualized with Coomassie Brilliant Blue R-250. Highly pure

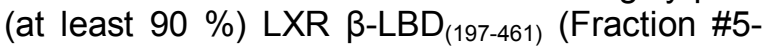
14) was obtained (Figure 5). The purified fraction was checked by MALDI-TOF mass spectrometer and confirmed the coincidence between theoretical predicted recombinant LXR $\beta-\mathrm{LBD}_{(197-}$ 461) molecular weight with that of the purified recombinant protein (Data not shown).

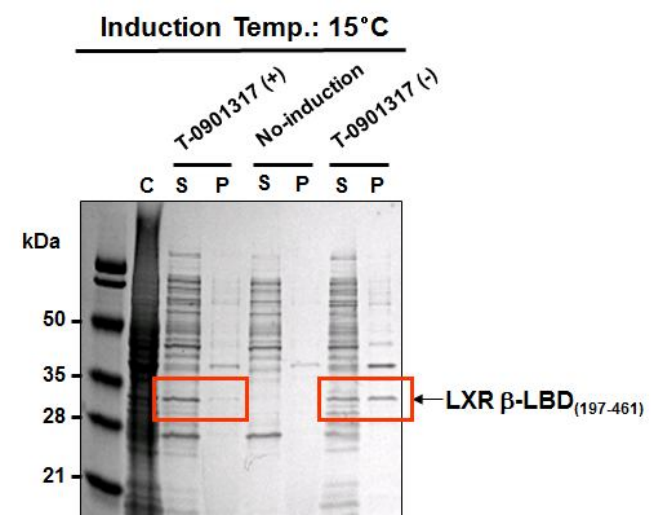

Figure 4: SDS-PAGE analysis of recombinant fusion protein expression (LXR $\left.\beta-\operatorname{LBD}_{(197-461)}\right)$ by adding a synthetic agonist, T-0901317, into the culture with the inducer, anhydrotetracycline. Soluble (S) and insoluble (P) recombinant LXR $\beta-\operatorname{LBD}_{(197-461)}$ fusion protein induced or uninduced at $15^{\circ} \mathrm{C}$ in the presence or absence of T-0901317, separated by SDS-PAGE and stained with Coomassie Blue R-250. The boxed region and the arrow indicated the position of the recombinant $L X R \quad \beta-\operatorname{LBD}_{(197-461)}$ fusion protein. Lane $C$ represents the total extract from the uninduced $E$. coli cells

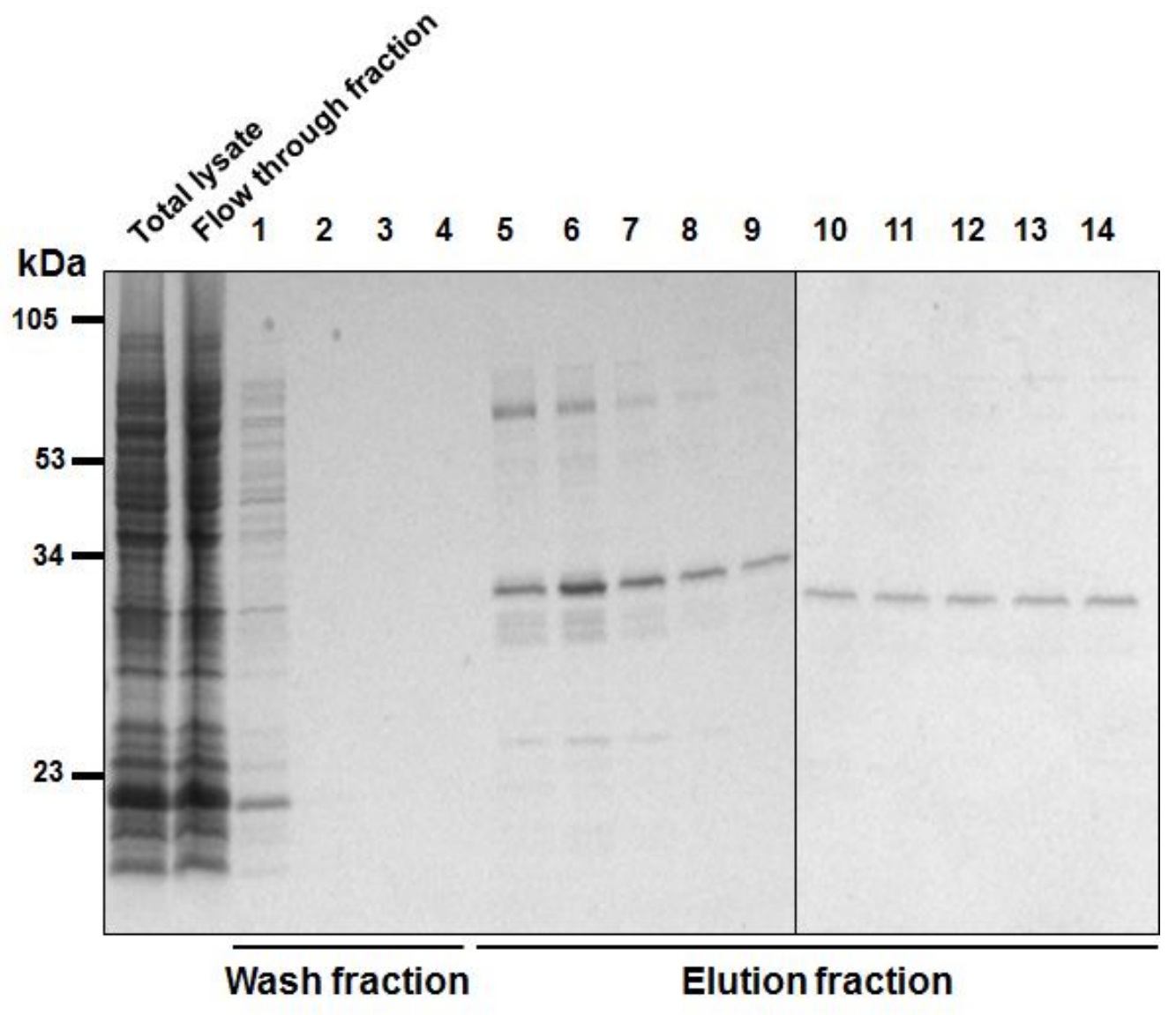

Figure 5: Purification of recombinant LXR $\beta$-LBD using a tetracyline-inducible pPROTet.E HN vector. $E$. coli cells, transformed with various $L X R \beta-\operatorname{LBD}_{(197-461)}$, were harvested after induction at $15^{\circ} \mathrm{C}$. The (His) $)_{6}$-fused $L X R$ $\beta$-LBD $(197-461)$ proteins obtained using $\mathrm{Ni}^{+2}$-NTA-agarose column were cleaved by thrombin. $\operatorname{LXR} \beta-\operatorname{LBD}_{(197-461)}$ was purified, separated by SDS-PAGE and visualized with Coomassie Brilliant Blue R-250 


\section{Analysis of ligand binding}

Varied concentrations of the purified recombinant LXR $\beta$-LBD in the presence or absence of $T$ 0901317 were incubated at room temperature with a europirim-labeled peptide. The polarization degrees (FI) were measured with an excitation wavelength set at $615 \mathrm{~nm}$ and an emission wavelength set at $665 \mathrm{~nm}$. Figure 6 shows typical dose-response curve obtained by using increasing concentrations of the purified recombinant $L X R \beta-\operatorname{LBD}_{(197-461)}$ and measuring $\mathrm{FI}$ as an index of fluorescent peptide binding to LBD. This type of experiment was repeated a number of times during the course of the study, allowing to calculate an $\mathrm{ED}_{50}$ of $533 \mathrm{nM}$ (Figure 6 ). Since our assays performed on the condition of only the purified recombinant LXR $\beta-\mathrm{LBD}_{(197-}$ 461) protein, it is likely that the true values are somewhat lower. Thus, we suggest that the expression using pPROTet.E HN vector with an hydrotetracycline induction at low temperature of $15^{\circ} \mathrm{C}$ is found in production of the soluble LXR $\beta$-LBD and should be useful for biological and structural analyses.

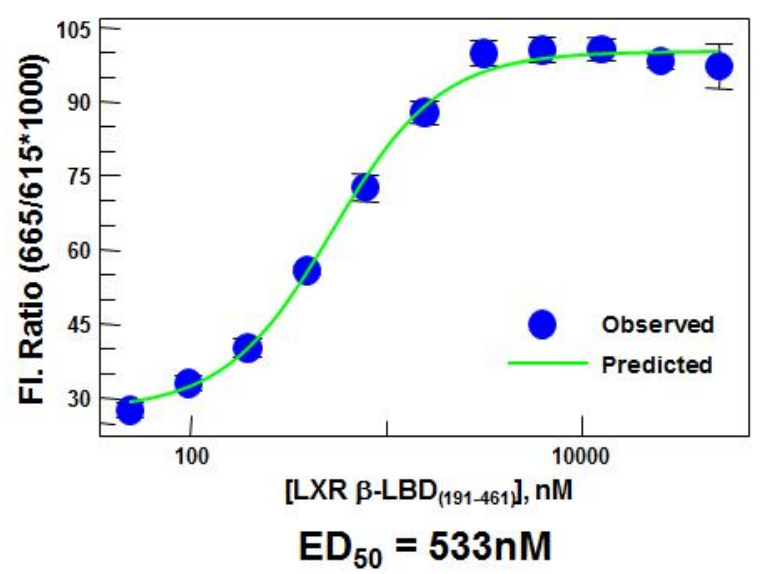

Figure 6: Ligand-binding studies of purified recombinant LXR $\beta$-LBD using fluorescence polarization assay. Fluorescence polarization assay in the direct binding of probes to synthesized and purified LXR $\beta-\operatorname{LBD}_{(197-461)}$ by the coactivator peptide (SRC-1a, CPSSHSSLTERHKILHRLLQEGSPS,

Cosmo Genetech Co., Seoul, Korea) and the acceptor APC was performed using the method described as in the "Experimental" section. The polarization degree FI was plotted against the LXR $\beta$-LBD concentration and nonlinear regression analysis was performed to determine the $E D_{50}$. Data is mean $\pm S D(n=3)$ and has been repeated thrice. The $E D_{50}$ was calculated to be $533 \mathrm{nM}$ of LXR $\beta-\operatorname{LBD}_{(197-461)}$

\section{DISCUSSION}

In spite of a number of advantages of expression in E. coli, heterologous gene expression in E. coli can lead to the production of insoluble and/or nonfunctional target proteins as well as low level of expression. The effect of temperature on protein folding has been well documented and is one of the most common factors to be optimized during protein expression [14]. Interestingly, it was reported that the stabilization of recombinant G-protein coupled receptors (GPCRs) in micelles by cholesteryl hemisuccinate (CHS) has been described previously during its expression and purification procedures [15-17]. The production of insoluble and/or nonfunctional target proteins is often due to the absence of cofactors or posttranslational modifications required for function, stability or folding. Coexpression of multiple genes in E. coli, especially the members of a stable multiprotein complex needs special strategies for the availability of large quantity of the target protein, the biological activities and the stability over extended periods of time. In many cases, overexpression of nuclear receptor resulted in mostly in inclusion bodies with the residual soluble component unable to interact with its partner, RXR or their ligands [18-20]. The successful attempt to preserve the biological activity and the high solubility of recombinant LXR relied on the coexpression of nuclear receptor partners, such as RXR-RAR LBD and ecdysone receptor (ECR)-ultraspiracle (USP) LBD [20]. They showed that, as with RXR, production of soluble ECR is dramatically improved by coexpression with USP, suggesting that this coexpression strategy provides a general approach to the study of the biophysical and structural properties of the nuclear receptor complexes.

The three dimensional structure of LXR $\beta$-LBD was already solved. According to their demonstration, expression of LXR $\beta$-LBD in $E$. coli yielded predominantly insoluble protein. The soluble fraction was unstable and could not be suitably concentrated for protein crystallization. $E$. coli remains the most efficient widely-used host for recombinant protein production. The main factors that contribute to the selection of $E$. coli as host for the expression of recombinant protein are well-defined genetics, high transformation efficiency. In fact, preparations enriched by a specific protein are rarely easily obtained from natural host cells. Hence, recombinant protein production is frequently the sole applicable procedure. With the advent of the post-genomic era has come the need to express 
in this bacterium a growing number of genes originating from different organisms. Although often simple for soluble proteins, recombinant fusion partners and mutant strains have advanced the possibilities with E. coli.

In this study, we demonstrate that the synthetic agonist for LXR can alleviate these problems. Thus, we suggest that this strategy may represent an approach to high level of expression of nuclear receptor heterodimers. The actions of lipophilic hormones, including steroids, retinoids, thyroid hormone and vitamin D3, are mediated through a conserved superfamily of nuclear receptor proteins that function as ligandregulated, DNA-binding transcriptional activators [26]. LXRs were initially described as orphan receptors and later mono oxygenated cholesterol derivatives, oxysterols, were identified as their natural ligands [6]. Recently, two nonsteroid synthetic LXR agonists, T-0901316 and GW3965, have been wildly used as nonsteroial chemical tools to explore the biology of LXRs. T0901317 activates both LXR $\alpha$ and LXR $\beta \square$ whereas GW3965 has a greater affinity for $L X R$ $\beta$ than for LXR $\alpha$ [20]. In this study, we used T0901317 as an agonist to evaluate the biological activity of the recombinant LXR $\beta$-LBD. The effects of T-0901317 on the interaction of the coactivator peptide (SRC-1a, CPSSHSSLTERHKILHRLLQEGSPS) and the acceptor APC with the recombinant LXR $\beta$-LBD protein were determined by fluorescence polarization assays.

\section{CONCLUSION}

In summary, we have successfully expressed and purified the recombinant LXR $\beta$-LBD proteins in $E$. coli using a tetracycline inducible system. The recombinant LXR $\beta$-LBDs are substantially soluble and should be useful for future biological, biophysical and structural analyses of nuclear receptor complexes. We suggest that this may represent a new approach to high expression of other nuclear receptors and may be useful as well for other classes of heterodimeric protein partners. In addition, this result provides that this recombinant LXR $\beta$-LBD protein will be a promising target for the development of molecular ligands with improved therapeutic windows.

\section{REFERENCES}

1. Mangelsdorf DJ, Evans RM. The RXR heterodimers and orphan receptor. Cell 1995; 83: 841-850.
2. Mangelsdorf DJ, Thummel $C$, Beato $M$, Herrlich $P$, Schütz G, Umesono K, Blumberg B, Kastner P, Mark $M$, Chambon $P$, et al. The nuclear receptor superfamily: the second decade. Cell 1995; 83: 835839.

3. McKenna NJ, Lanz RB, O'Malley BW. Nuclear receptor coregulators: cellular and molecular biology. Endocr Rev. 1999; 20: 321-344.

4. Willy PJ, Umesono K, Ong ES, et al. LXR, a nuclear receptor that defines a distinct retinoid response pathway. Genes Dev. 1995; 9: 1033-1045.

5. Repa JJ, Mangelsdorf DJ. The role of orphan nuclear receptors in the regulation of cholesterol homeostasis. Ann Rev Cell Dev Biol. 2000; 16: 459481.

6. Janowski BA, Willey PJ, Rama-Devi T, et al. An oxysterol signalling pathway mediated by the nuclear receptor LXR $\square$. Nature 1996; 383: 728-731.

7. Alberti S, Schuster G, Parini P, et al. Hepatic cholesterol metabolism and resistance to dietary cholesterol in LXR $\square$-deficient mice. J Clin Invest. 2001; 107: 565573.

8. Glass CK, Rosenfeld MG. The coregulator exchange in transcriptional functions of nuclear receptors. Genes Dev. 2000; 14: 121-141.

9. Xu EH, Lambert MH, Montana VG, et al. Structural determinants of ligand binding selectivity between the peroxisome proliferator-activated receptors. Proc Natl Acad Sci USA. 2001; 98: 13919-13924.

10. Venkateswaran $A$, Laffitte $B A$, Joseph $S B$, et al. Control of cellular cholesterol efflux by the nuclear oxysterol receptor LXR $\square$. Proc Natl Acad Sci USA. 2000; 97: 12097-12102.

11. Quinet EM, Savio DA, Halpern AR et al. Liver $X$ receptor $(L X R) \quad \square$ regulation in $L X R \quad \square \square$ deficient mice: implications for therapeutic targeting. Mol Pharm. 2006; 70: 1340-1349.

12. Dagher $R$, Pigault $C$, Bonnet $D$, et al. Use of a fluorescence polarization based high throughput assay to identify new calmodulin ligands. Biochim Biophys Acta 2006; 1763: 1250-1255.

13. Lévy-Bimbot $M$, Major $G$, Courilleau $D$, et al. Tetrabromobisphenol-A disrupts thyroid hormone receptor $\square$ function in vitro: Use fluorescence polarization to assay corepressor and coactivator peptide binding. Chemosphere 2012; 87: 782-788.

14. Williams S, Bledsoe RK, Collins JL, et al. X-ray crystal structure of the liver $X$ receptor $\square$ ligand binding domain. J Biol Chem. 2003; 278: 27138-27143.

15. Grisshammer $R$, Averbeck $P$, Sohal AK. Improved purification of a rat neurotensin receptor expressed in Escherichia coli. Biochem Soci Trans. 1999; 27: 899903.

16. Kobika BK. G protein coupled receptor structure and activation. Biochem Biophys Acta 2007; 1768: 794807.

17. Vulotti K, Kimura $T$, Macke $L$, et al. Stabilization of functional recombinant cannabinoid receptor $C B 2$ in

Trop J Pharm Res, August 2014; 13(8): 1254 
detergent micelles and lipid bilayers. PLoS One 2012; 7: e46290.

18. Yang $N$, Schüle $R$, Mangersdorf $D J$, et al. Characterization of DNA binding and retinoic acid binding properties of retinoic acid receptor. Proc Natl Acad Sci USA. 1991; 88: 3559-3563.
19. Chen ZP, Shemsshedini L, Durand L, et al. Pure and functionally homogenous recombinant retinoid $X$ receptor. J Biol Chem. 1994; 269: 18662-18667.

20. Li C, Schwabe JW, Banayo E, et al. Coexpression of nuclear receptor partners increases their solubility and biological activities. Proc Natl Acad Sci USA. 1997; 94: 2278-2283. 